\title{
Vulvar Adenocarcinoma of Mammary Gland Type
}

National Cancer Institute

\section{Source}

National Cancer Institute. Vulvar Adenocarcinoma of Mammary Gland Type. NCI

Thesaurus. Code C128162.

A primary invasive malignant epithelial neoplasm of the vulva showing morphological

features of recognized breast adenocarcinomas. (WHO, 2014) 